\title{
COMPARATIVE EFFECTIVENESS OF MECHANICAL BOWEL PREPARATION WITH AND WITHOUT ORAL ANTIBIOTICS FOR ELECTIVE COLORECTAL SURGERY
}

By

\author{
Abd Allah Barakat Abd Allah Bassuny, Mohammad Mohsen Salem and \\ Ayman Helmy Ebrahim \\ Department of General Surgery, Faculty of Medicine, Al-Azhar University \\ Corresponding author: Abdallah Barakat Abdallah Bassuny, \\ E-mail: abdallah_bassuny9090@gmail.com
}

\begin{abstract}
Background: Surgical site infections (SSI) are a major cause of morbidity after surgery and are associated with increased hospital length of stay, readmissions, costs, and mortality. Surgical site infections are disproportionally high in colorectal surgery and are estimated to affect between $15 \%$ and 30\% of patients. Surgical site infections (SSIs) increase the cost of care and are associated with increased morbidity and mortality and it is the third most common nosocomial infection.
\end{abstract}

Objective: To clarify oral antibiotics (OAs) use together with mechanical bowel preparation (MBP) patients outcome following elective colorectal surgery.

Patients and methods: The current study was conducted at Al-Hussein University Hospital and Kafr Elsheikh General Hospital. We selected forty patients who underwent elective colorectal surgery. All the studied patients were divided into two equal groups: Group I received mechanical bowel preparation with oral antibiotics, and Group II received mechanical bowel preparation with oral antibiotics.

Results: We found that there was no significant difference between two groups of patients as regards mean age and sex distribution. Anterior resection was the most frequent surgical procedure done for the two studied groups of patients. The least frequent procedures done for group I patients were radical sigmoidectomy. Total colectomy and sigmoidectomy, the least frequent procedures done for group II patients, were total colectomy and extended right hemicolectomy. However, the difference between the two groups of patient as regards type of surgery and time of closure did not reach the significant value. All studied patients had ileostomy as a type of stoma. As regards complications after surgery, the most frequent complications among patients of group I were pneumonia and ileus. On the other hand, the most frequent complications among patients of Group II were ileus, leakage and intra-abdominal collection. The mean values of hospital stay in days significantly decreased among patients of group 1.

Conclusion: Current study suggested a potentially significant role for prophylactic preoperative oral antibiotic in addition to mechanical bowel preparation, in the prevention of postoperative complications during elective colorectal surgery.

Keywords: Mechanical Bowel Preparation, Oral Antibiotics, Elective Colorectal Surgery. 


\section{INTRODUCTION}

Mechanical bowel preparation (MBP) for colorectal surgery aims to reduce fecal mass and bacterial count with the objective to decrease surgical site infections (SSI) rate, including anastomotic leakage (AL) (Alice and Yves, 2019). Surgical-site infection (SSI) is a challenging problem following colorectal surgery. SSI can be separated into superficial and deep components, and is reported routinely until 30 days after surgery. SSI represents not only a costly expense to health services, but more importantly influences patient recovery and survival (Garner and Anderson, 2016).

The use of mechanical bowel preparation (MBP) in combination with oral antibiotics became routine practice in the 1970s, with Nichols' and Condon's preparation emerging as the standard preoperative regimen. A significant body of evidence supported its use in reducing the high level of postoperative septic complications associated with colorectal surgery (Kiran et al., 2015).

Surgical site infections (SSIs) are commonly diagnosed as postoperative complications related to all abdominal operations with an estimated rate of $26 \%$. In colorectal surgery (Mik et al., 2016).

Patients who receive MBP plus oral antibiotics before colon surgery have a lower incidence of superficial SSI, deep SSI, organ space SSI, any SSI, anastomotic leakage, postoperative ileus, sepsis, re-admission, and reoperation compared with patients who receive neither (Koller et al., 2017). Moghadamyeghaneh et al. reported that combination of MBP and oral antibiotics significantly decreased risk of overall morbidity, superficial SSI, anastomotic leakage, and intra-abdominal infections in patients undergoing resection of the left colon (Moghadamyeghaneh et al., 2015). However, oral antibiotics alone have been reported to reduce SSI, anastomotic leakage, postoperative ileus, and major morbidity after elective colorectal surgery (Garfinkle et al., 2017).

Many studies have identified a reduced risk of anastomotic leakage following preoperative MBP with additive oral antibiotics. When patients accepted bowel preparation before surgery. Adding three doses of OAs is associated with lower patient tolerance in terms of increased nausea, vomiting, and abdominal pain; furthermore, the advantage of OAs in the prevention of postoperative septic complications remains unknown (Sun et al., 2018).

The purpose of this study was to compare the effectiveness of oral antibiotics (OAs) with mechanical bowel preparation (MBP) with or without oral antibiotics \& elective colorectal surgery.

\section{PATIENTS AND METHODS}

This was a prospective clinical study, comparing between effectiveness of mechanical bowel preparation with and without oral antibiotics for elective colorectal surgery. The current study was conducted at Al-Hussein University Hospital and Kafr Elsheikh General Hospital. We selected patients who underwent elective colorectal surgery.

All the studied patients were divided into two equal groups: Group I received mechanical bowel preparation with oral antibiotics, and Group II received 
mechanical bowel preparation with oral antibiotics.

Ethical consideration: All participants were volunteers and signed written informed consents that explained the aim of study before the study initiation. Approval was obtained from ethical committee of General Surgery Department.

Inclusion criteria: Colon cancer, ectal cancer, diverticulitis, inflammatory bowel disease, benign polyps and accepted general anesthesia and received bowel preparation.

Exclusion criteria: Patients who underwent an emergent operation, colonoscopy, colostomy or closure of colostomy and received preoperative chemoradiotherapy. IV sedation or local anesthesia and the patients who did not complete the bowel preparation.

All patients who fulfill the eligibility criteria were subjected to:

- History taking with emphasis on name age, gender, indications, type of surgery.

- General examination to exclude any medical disease with special attention to blood pressure, pulse and temperature.

- Abdominal examination including digital rectal examination (pr) and vaginal examination (PV) in female.

- Vital signs: including pulse, blood pressure, temperature, and respiratory rate) were recorded in every patient.

- Electrocardiogram (ECG) and echocardiography.
- Imaging investigations:

- Plain chest-x-ray to exclude metastasis, and as a part of patient general evaluation.

- Pelvi abdominal US ultrasound was the study of choice for primary evaluation of abdominopelvic lesion.

- Pelvi abdominal CT with oral and IV contrast to assess for any sites of disease.

Patients were admitted 2 days before the surgery and received a low-residue soft diet following admission, and were switched to a clear liquid diet the next day. Parenteral hydration was commenced $13 \mathrm{~h}$ before the surgery. MBP was performed through oral administration of $45 \mathrm{~mL}$ of sodium dibasic phosphate solution (Fleet Phospho soda) with water, and a rectally applied water enema. Both groups received cefazolin $1 \mathrm{~g}$ IV during the induction of anesthesia. Also, patients in Group1 received OAs which consisted neomycin $(1 \mathrm{~g})$ and an erythromycin $(1 \mathrm{~g})$ at $1 \mathrm{pm}, 2 \mathrm{pm}$, and $11 \mathrm{pm}$ the day before surgery.

All patients received general anesthesia. Nasogastric tube and foley's catheter was inserted together with elastic stockings for prophylaxis against lower limb deep vein thrombosis. The abdominal wall was approximated using a continuous $1-0$ polydioxanone suture, and the skin was subsequently closed using interrupted 3-0 nylon sutures or clips.

Each patient was followed for 30 days postoperatively through weekly clinic visits where wounds were assessed for infection and anastomotic leakage. The length of hospitalization was calculated as 
the period from the day of surgery until discharge. Hospital death was defined as mortality from any cause within 30 days of hospitalization.

\section{Statistical Analysis:}

The collected data were revised, organized, tabulated and statistically analyzed using statistical package for the social sciences (SPSS) version 22.0 for windows. Data are presented as the Mean \pm standard deviation (SD), frequency, and percentage. Continuous normally distributed data were compared by the Student's t test (two-tailed). The level of significance was accepted if the $\mathrm{P}$ value $\leq$ 0.05 .

\section{RESULTS}

The current study included 40 patients who underwent elective colorectal surgery. All underwent bowel preparation before surgery. The studied patients were classified into two groups according to antibiotic administration before surgery:

Group I: Twenty patients who underwent mechanical bowel preparation with oral anti biotic. They were 15 males and 5 females with mean age of $50.60 \pm 12.45$.
Group II: Twenty patients who underwent mechanical bowel preparation without oral anti biotic. They were 11 males and 9 females with mean age of $48.50 \pm 8.94$.

There was no significant difference between two groups of patients as regards mean age and sex distribution (Table 1).

Table (1): Distribution of age and sex among studied two groups of patients

\begin{tabular}{|l|l|c|c|c|}
\hline \multirow{2}{*}{ Variables } & Groups & \multicolumn{1}{c|}{$\begin{array}{c}\text { Group I } \\
\text { No.= 20 }\end{array}$} & $\begin{array}{c}\text { Group II } \\
\text { No.= 20 }\end{array}$ & \multirow{2}{*}{ P-value } \\
\hline \multirow{2}{*}{ Age $($ years) } & Mean \pm SD & $50.60 \pm 12.45$ & $48.50 \pm 8.94$ & \multirow{2}{*}{0.544} \\
\cline { 2 - 4 } & Range & $26-66$ & $30-64$ & \\
\hline \multirow{2}{*}{ Gender } & Female & $5(25.0 \%)$ & $9(45.0 \%)$ & \multirow{2}{*}{0.185} \\
\cline { 2 - 4 } & Male & $15(75.0 \%)$ & $11(55.0 \%)$ & \\
\hline
\end{tabular}

*:Chi-square test; $\bullet:$ Independent t-test

As regards the distribution of underlying causes of colon diseases, there was no significant difference between the two studied groups of patients. Cancer of sigmoid colon and adenocarcinoma have the highest frequency among group I patients. On the other hand, cancer rectum and cancer sigmoid have the highest frequency among Group II Patients. Stage $\mathrm{t} 2 \mathrm{n} 0 \mathrm{~m} 0$ was the most prevalent among the two groups of patients. The lowest prevalent stage among all studied patients was $\operatorname{tn} 2 \mathrm{~m} 0$. The difference between the two groups of patients did not reach the significant level. All patients have score II of ASA (Table 2). 
Table (2): Comparison between two studied groups of patients as regards colon diseases, stage and ASA score

\begin{tabular}{|c|c|c|c|}
\hline $\begin{array}{ll}\text { Variables } & \text { Groups } \\
\end{array}$ & $\begin{array}{l}\text { Group I } \\
\text { No. }=20\end{array}$ & $\begin{array}{l}\text { Group II } \\
\text { No. = 20 }\end{array}$ & P-value \\
\hline $\begin{array}{l}\text { Type of disease: } \\
\text { Cancer rectum No. }(\%) \\
\text { Cancer sigmoid No. }(\%) \\
\text { Ulcerative colitis No. }(\%) \\
\text { Colon Aden carcinoma No. }(\%) \\
\text { Cecum Aden carcinoma No. }(\%)\end{array}$ & $\begin{array}{c}5(25.0 \%) \\
7(35.0 \%) \\
1(5.0 \%) \\
7(35.0 \%) \\
0(0.0 \%) \\
\end{array}$ & $\begin{array}{l}6(30.0 \%) \\
6(30.0 \%) \\
1(5.0 \%) \\
3(15.0 \%) \\
4(20.0 \%) \\
\end{array}$ & 0.217 \\
\hline $\begin{array}{l}\text { Stage: } \\
\text { t1n2m0 No. }(\%) \\
\text { t2n0m0 No. }(\%) \\
\text { t2n1m0 No. }(\%) \\
\text { t2n2m0 No. }(\%) \\
\text { t3n1m0 No. }(\%) \\
\text { t3n2m0 No. }(\%)\end{array}$ & $\begin{array}{l}0(0.0 \%) \\
9(45.0 \%) \\
3(15.0 \%) \\
6(30.0 \%) \\
0(0.0 \%) \\
1(5.0 \%)\end{array}$ & $\begin{array}{l}1(5.0 \%) \\
7(35.0 \%) \\
3(15.0 \%) \\
5(25.0 \%) \\
1(5.0 \%) \\
2(10.0 \%)\end{array}$ & 0.848 \\
\hline $\begin{array}{l}\text { ASA score } \\
\text { II }\end{array}$ & $20(100.0 \%)$ & $20(100.0 \%)$ & - \\
\hline
\end{tabular}

$*$ :Chi-square test.

Anterior resection was the most frequent surgical procedure done for the two studied groups of patients. The least frequent procedures done for group I patients were radical sigmoidectomy, total colectomy and sigmoidectomy. The least frequent procedures done for group II patients were total colectomy and extended right hemicolectomy. However, the difference between the two groups of patient as regards type of surgery and time of closure did not reach the significant value. All studied patients had ileostomy as a type of stoma (Table 3 ).

Table (3): Comparison between two studied groups of patients as regards surgery, time of closure and type of stoma

\begin{tabular}{|c|c|c|c|c|}
\hline \multicolumn{2}{|c|}{ Variables $\quad$ Groups } & $\begin{array}{l}\text { Group I } \\
\text { No. }=20\end{array}$ & $\begin{array}{l}\text { Group II } \\
\text { No. }=20\end{array}$ & $\begin{array}{c}\text { P- } \\
\text { value }\end{array}$ \\
\hline \multirow{6}{*}{ Surgery: } & Anterior resection No. (\%) & $10(50.0 \%)$ & $13(65.0 \%)$ & \multirow{6}{*}{0.590} \\
\hline & Rt hemicolectomy No. $(\%)$ & $7(35.0 \%)$ & $5(25.0 \%)$ & \\
\hline & Radical sigmoidectomy No. (\%) & $1(5.0 \%)$ & $0(0.0 \%)$ & \\
\hline & Total colectomy No $(\boldsymbol{\%})$ & $1(5.0 \%)$ & $1(5.0 \%)$ & \\
\hline & Sigmoidectomy No $(\%)$ & $1(5.0 \%)$ & $0(0.0 \%)$ & \\
\hline & Extended Right hemicolectomy No (\%) & $0(0.0 \%)$ & $1(5.0 \%)$ & \\
\hline \multirow{2}{*}{\multicolumn{2}{|c|}{$\begin{array}{l}\text { Time of cl } \\
\text { Median } \\
\text { Range } \\
\end{array}$}} & $23(6-43)$ & $12(8-16)$ & \multirow{2}{*}{0.164} \\
\hline & & $2-83$ & $8-16$ & \\
\hline \multicolumn{2}{|c|}{$\begin{array}{l}\text { Type of stoma: } \\
\text { Ileostomy }\end{array}$} & $20(100.0 \%)$ & $20(100.0 \%)$ & - \\
\hline
\end{tabular}


As regards complication after surgery, the most frequent complications among patients of group I were pneumonia and ileus. On the other hand, the most frequent complications among patients of Group II were ileus, leakage and intra-abdominal collection. The lowest frequent complications among patients of group I were deep venous thrombosis and urinary tract infection. The lowest frequent complication among patients of Group II was pneumonia. After all, the difference between the studied groups of patients as regards complications showed significant value $(\mathrm{p}=0.028)$. Although ileus, wound infection, leakage, intra-abdominal collection, urinary tract infection and wound dehiscence were more frequent among patients of group II. The difference between the two studied groups did not reach the significant level (Table 4).

Table (4): Comparison between two studied groups of patients as regards complications after surgery

\begin{tabular}{|l|c|c|c|}
\hline Complications & $\begin{array}{c}\text { Group I } \\
\text { No.= 20 }\end{array}$ & $\begin{array}{c}\text { Group II } \\
\text { No. = 20 }\end{array}$ & P-value \\
\hline No & $\begin{array}{c}8(40.0 \%) \\
\text { Yes }\end{array}$ & $\begin{array}{c}2(10.0 \%) \\
12(60.0 \%)\end{array}$ & $0.028^{*}$ \\
\hline Type of complications: & \multicolumn{3}{|l|}{} \\
\hline Pneumonia & $4(20.0 \%)$ & $3(15.0 \%)$ & 0.677 \\
\hline Ileus & $4(20.0 \%)$ & $6(30.0 \%)$ & 0.465 \\
\hline Wound infection & $3(15.0 \%)$ & $4(20.0 \%)$ & 0.677 \\
\hline Leakage & $3(15.0 \%)$ & $6(30.0 \%)$ & 0.256 \\
\hline Intraabdominal collection & $3(15.0 \%)$ & $6(30.0 \%)$ & 0.256 \\
\hline Deep venous thrombosis & $2(10.0 \%)$ & $0(0.0 \%)$ & 0.147 \\
\hline Urinary tract infection & $2(10.0 \%)$ & $6(30.0 \%)$ & 0.114 \\
\hline Wound dehiscence & $1(5.0 \%)$ & $3(15.0 \%)$ & 0.292 \\
\hline
\end{tabular}

$\diamond$ :Chi-square test. $\bullet:$ Independent t-test

Distribution of diabetes mellitus, hypertension, ischemic heart diseases, COPD or bronchial asthma as co morbid diseases among the two studied groups of patients did not show any significant differences between the two groups. The most frequent diseases were diabetes mellitus and hypertension (Table 5).

Table (5): Comparison between two studied groups of patients as regards co morbid diseases

\begin{tabular}{|c|c|c|c|c|c|}
\hline Co morbidities $\quad$ Groups & \multicolumn{2}{|c|}{$\begin{array}{l}\text { Group I } \\
\text { No. }=20\end{array}$} & \multicolumn{2}{|c|}{$\begin{array}{l}\text { Group II } \\
\text { No. = 20 }\end{array}$} & P-value \\
\hline No (No \& \%) & 9 & $45.0 \%$ & 9 & $45.0 \%$ & \\
\hline Yes (No \& \%) & 11 & $55.0 \%$ & 11 & $55.0 \%$ & 1.000 \\
\hline HTN (No \& \%) & 7 & $35.0 \%$ & 7 & $35.0 \%$ & 1.000 \\
\hline DM (No \& \%) & 4 & $20.0 \%$ & 6 & $30.0 \%$ & 1.000 \\
\hline $\begin{array}{l}\text { Ischaemic heart disease } \\
\text { (No \& \%) }\end{array}$ & 2 & $10.0 \%$ & 1 & $5.0 \%$ & 0.548 \\
\hline COPD (No \& \%) & 1 & $5.0 \%$ & 0 & $0.0 \%$ & 0.311 \\
\hline Broncial asthma (No \& \%) & 1 & $5.0 \%$ & 1 & $5.0 \%$ & 1.000 \\
\hline
\end{tabular}


The mean values of hospital stay in days significantly decreased among patients of group 1 (Table 6).

Table (6): Mean values of hospital stay in days among the studied groups of patients.

\begin{tabular}{|l|c|c|c|}
\hline $\begin{array}{l}\text { Hospital stay Groups } \\
\text { [days] }\end{array}$ & $\begin{array}{c}\text { Group I } \\
\text { No. = 20 }\end{array}$ & $\begin{array}{c}\text { Group II } \\
\text { No. = 20 }\end{array}$ & P-value \\
\cline { 1 - 3 } Mean \pm SD & $15.15 \pm 6.75$ & $21.75 \pm 9.95$ & \multirow{2}{*}{0.019} \\
\hline Range & $10-35$ & $10-38$ & \\
\hline
\end{tabular}

DISCUSSION

The current study included 40 patients who underwent elective colorectal surgery. All underwent bowel preparation before surgery. The studied patients were classified into two equal groups according to antibiotic administration before surgery: Group I underwent mechanical bowel preparation with oral antibiotic. They were 15 males and 5 females with mean age of $50.60 \pm 12.45$. Group II underwent mechanical bowel preparation without oral anti biotic. They were 11 males and 9 females with mean age of $48.50 \pm 8.94$.

Mik and his Colleagues (2016) concluded that the mode of disease presentation compels the surgeon to perform surgery in urgent course. The operation on patients with peritonitis is associated with a higher risk of wound contamination, predominantly because of the heavy bacterial load of the colon and rectum. Additionally, the preparation to the urgent operation does not allow us to use all components of preoperative antibacterial prophylaxis. In our study, these patients did not receive MBP with $\mathrm{ABX}$, which could bring higher incidence of SSIs.

In the current study, all studied patients underwent mechanical preparation of bowel before surgery as a routine technique to decrease risk of postoperative complications. In the same context, Cawich and his Colleagues (2017) suggested that although it initially appeared logical that reducing faecal load in the colon would reduce infectious morbidity and anastomotic failures. Mucosa associated bacteria are found within the epithelium and they may be adherent to or trapped in mucus lining the colonic wall. While MPB physically evacuates faeces and bacteria from the lumen, there is insignificant effect on mucosa associated bacteria (Nelson et al., 2015).

Peter et al. (2019) used animal models to study intraoperative colonic lavage. In their study, they used tissue cultures to quantitatively assess the counts of intraluminal and mucosa associated bacteria. They demonstrated 10000 fold reductions in intraluminal bacteria but insignificant changes in mucosaassociated bacteria. This strengthened the theory that the intramucosal environment was a separate ecologic niche. These findings explain the definite role of preoperative prophylactic antibiotics to decrease post-operative morbidity among patients who undergo colorectal surgery. So that, prophylactic preoperative antibiotic should be added to mechanical 
bowel preparation to control mucosa associated bacteria. Consequently, postoperative complications as anastigmatic leakage, ileus and wound infection will be decreased.

Previous study reported that the incidence of anastomotic leakage in patients undergoing MBP was reported to be 0\%-9.7\% (Fujita et al., 2011). Moreover, lower rectal anastomoses have been shown to have a higher risk of leakage (Moran and Heald, 2010). In the current study we found that the difference between the studied groups of patients as regards complications showed significant value. Leakage and wound dehiscence were more frequent among patients of group II. Our findings were supported by study of Suleyman and his colleagues (2016) who reported that although half of the patients in each group underwent low anterior resection with a lower rectal anastomosis. The rate of anastomotic dehiscence in patients who received preoperative oral antibiotics (Group A) was only $2 \%$. This result was much better than that of most other series. However, if oral antibiotics were not included as part of the preoperative bowel preparation (Group B), the anastomotic dehiscence rate increased up to $11 \%$.

A previous meta-analysis study has provided evidence to suggest that MBP and $\mathrm{OAB}$ should be given serious consideration in patient's under-going elective colorectal surgery to reduce the risk of SSI. In addition, it has shown that the combination of MBP and $\mathrm{OAB}$ is associated with significant reductions in anastomotic leak rates, 30-day mortality, overall morbidity, and the incidence of postoperative ileus, without increasing the risk of developing $\mathrm{C}$ difficile infection (Rollins et al., 2019). Its findings are in contradiction with previousmeta-analyses (Rollins et al., 2018) that did not account for the role of luminal antibiotics and showed that MBP on its own was of no benefit when compared with no bowel preparation or rectal enemas alone (Slim et al., 2010).

In the present study, adequate fluid and electrolyte replacement was started 8-12 h before surgery, and no major problems related to fluid or electrolyte imbalance occurred. Maintenance of normothermia, prevention of hypoglycemia and the timing of the beginning of oral supplementation were achieved by the same nursing team for the two groups of patients. In our study, we found that oral antibiotics caused a decrease in postoperative complications and hospital stay. This can be explained by the fact that oral antibiotics decrease the amount of bacteria found in the colon, which in turn, decreases the risk of infection. Although some authors proposed that preoperative antibiotics might result in bacterial super infection or resistance (Suleyman et al, 2016). We did not observe any adverse effects related to the pre-operative use of oral antibiotics in our patients.

In the present study, we found that the mean values of hospital stay in days among patients who received antibiotics before surgery was $15.15 \pm 6.75$. On the other hand, mean values of hospital stay in days among patients who did not received antibiotics before surgery was21.75 \pm 9.95. There was significant difference between two groups of patients. Our results were supported by findings of previous studies. Three cohort studies 
(Morris et al., 2015, Scarborough et al., 2015 and Koller et al., 2017), compared postoperative length of stay in patients given preoperative oral antibiotic prophylaxis, in combination with I.V. antibiotic prophylaxis and MBP, with that among patients given only I.V. antibiotic prophylaxis with MBP. There was significant heterogeneity between studies. Preoperative oral antibiotics were associated with a significantly shorter hospital stay.

Although many randomized studies and meta-analyses have already suggested that the adjunction of OA to systemic antibiotics reduced the risk of SSI before colorectal surgery (Chen et al., 2016). Hata et al. (2016) demonstrated that SSI reduced in patients receiving $\mathrm{OA}+\mathrm{SA}$ versus SA only. However in this study, patients included presented either colonic or rectal cancer, which is confusing for the interpretation of the results. Furthermore, MBP was given in some patients but was not assessed in this study. Similarly, Ikeda et al. published a RCT including. Also, colonic and rectal surgery, with approximately $85 \%$ of patients undergoing MBP in both groups making interpretation of the possible benefit of both OA + MBP impossible (Ikeda et al., 2016). Another RCT that focused only on patients with Crohn's disease (Uchino et al., 2019) scheduled to undergo intestinal resection with an open approach were randomly assigned to receive both preoperative OA and SA prophylaxis versus SA alone. The incidence of incisional SSI was significantly lower after OA + SA than after SA only: $7.4 \%$ vs $16.7 \%$. However, all the patients received MBP and both small bowel and colorectal surgery were included in the same study.
One of the concerns using possibly OA in all the patients undergoing colorectal surgery is the potential risk of Clostridium difficile (CD) infection. Al-Mazrou et al. (2018) evaluated the impact of OA on the development of $\mathrm{CD}$ infection in patients undergoing colectomy. $\mathrm{CD}$ occurs in $\approx 1$ to $7 \%$ of patients after colorectal surgery (Krapohl et al., 2013). Comparing patients with OA and MBP to those who did not, Al-Mazrou et al. (2018) showed that OA was associated with significantly lower postoperative CD infection and infectious complications, unplanned reoperations, mortality, length of stay and unplanned readmission. Also, on multivariate analysis, OA reduced the odds for CD infection after colectomy. Additionally, in subgroup analysis of patients who did not develop any postoperative infectious complication, OA was associated with lower risk of $\mathrm{CD}$ infection.

Alice and Yves (2019) concluded that there is a lot of evidence suggesting that $\mathrm{MBP}+\mathrm{OA}$ should be the new gold standard for colorectal surgery. But because randomized studies are still lacking, they do not know exactly if it is true for both colonic and rectal surgery. Furthermore, they still need to assess if only $\mathrm{OA}$ is enough or if both MBP and OA must be given to all the patients undergoing colorectal surgery. No randomized studies with homogeneous groups of patients are available in the literature. Patients undergoing rectal cancer surgery must be separate from those undergoing colonic cancer surgery. That is why randomized trials with specific arms are needed (Patchen, 2015). 


\section{CONCLUSION}

Preoperative combined oral antibiotics to mechanical bowel preparation should be applied as routine measure to patients undergoing elective colorectal surgery to control postoperative complications like anastomotic leakage, ileus and wound infection. Shorter duration of hospital stay, better prognosis and increase survival rate were achieved.

\section{REFERENCES}

1. Alice $F$ and Yves $P$ (2019): Bowel preparation in colorectal surgery: back to the future? Updates in Surgery, 71: 205-207.

2. Al-Mazrou AM, Hyde LZ and Suradkar K. (2018): Effect of inclusion or oral antibiotics with mechanical bowel preparation on the risk of Clostridium difficile infection after colectomy. J Gastrointest Surg., 22:1968-1975.

3. Cawich SO, Teelucksingh S, Hassranah S and Naraynsingh V. (2017): Role of oral antibiotics for prophylaxis against surgical site infections after elective colorectal surgery. World J Gastrointest Surg., 9(12): 246-255.

4. Chen M, Song $X$ and Chen LZ (2016): Comparing mechanical bowel preparation with both oral and systemic antibiotics ersus mechanical bowel preparation and systemic antibiotics alone for the prevention of surgical site infection after elective colorectal surgery: a meta-analysis of randomized controlled clinical trials. Dis Colon Rectum, 59:70-8.

5. Fujita S, Saito N, Yamada T, Takii Y, Kondo K, Ohue M, Ikeda M and Moriya Y. (2011): Randomized, multicenter trial of antibiotic prophylaxis in elective colorectalsurgery: single dose vs 3 doses of a second-generation cephalosporin without metronidazole and oral antibiotics. Arch Surg., 142: 657-661.

6. Garfinkle R, Abou-Khalil $\mathbf{J}$ and Morin $\mathbf{N}$. (2017): Is there a role for oral antibiotic preparation alone before colorectal surgery? ACS-NSQIP analysis by coarsened exact matching. Dis Colon Rectum., 60:729-37.
7. Garner BH and Anderson DJ. (2016): Surgical site infections: an update. Infect Dis Clin North Am., 30: 909-929.

8. Hata $H$, Yamaquchi $T$ and Hasegawa $S$. (2016): Oral and parenteral versus parenteral antibiotic prophylaxis in elective laparoscopic colorectal surgery (JMTO PREV 07-01): a phase 3, multicenter, open-label, randomized trial. Ann Surg., 263:1085-1091.

9. Ikeda A, Konishi T and Ueno M. (2016): Randomized clinical trial of oral and intravenous versus intravenous antibiotic prophylaxis for laparoscopic colorectal resection. BJS, 103:1608-1615

10. Kiran RP, Murray AC and Chiuzan C. (2015): Combined preoperative mechanical bowel preparation with oral antibiotics significantly reduces surgical site infection, anastomotic leak, and ileus after colorectal surgery. Ann Surg., 262:416-25.

11. Koller SE, Bauer KW, Egleston BL, Smith R, Philp MM and Ross HM. (2017): Comparative effectiveness and risks of bowel preparation before elective colorectal surgery. Ann Surg., 267: 734-732.

12. Krapohl GL, Morris AM and Cai S (2013): Preoperative risk factors for postoperative Clostridium difficile infection in colectomy patients. Am J Surg., 205:343-347.

13. Mik M, Berut M, Trzcinski R, Dziki L, Buczynski J and Dziki A. (2016): Preoperative oral antibiotics reduce infections after colorectal cancer surgery. Langenbecks Arch Surg., 401:1153-1162.

14. Moghadamyeghaneh Z, Hanna MH and Carmichael JC. (2015): Nationwide analysis of outcomes of bowel preparation in colon surgery. J Am Coll Surg., 220:912-20.

15. Moran BJ and Heald RJ (2010): Risk factors for, and management of anastomotic leakage in rectal surgery. Colorectal Dis., 3: 135-137.

16. Morris MS, Graham LA, Chu DI, Cannon JA and Hawn MT. (2015): Oral antibiotic bowel preparation significantly reduces surgical site infection rates and readmission rates in elective colorectal surgery. Ann Surg., 261:1034-1040. 
17. Nelson RL, Gladman $\mathbf{E}$ and Barbateskovic M. (2015): Antimicrobial prophylaxis for colorectal surgery. Surgery, 158: 66-77.

18. Patchen DE (2015): Should a scheduled colorectal operation have a mechanical bowel prep, preoperative oral antibiotics, both, or neither? Ann Surg., 261:1041-1043

19. Peter C, Zarras K, Stodolski M, Wirjawan I and Zirngibl $\mathbf{H}$ (2019): Routine preoperative mechanical bowel preparation with additive oral antibiotics is associated with a reduced risk of anastomotic leakage in patients undergoing elective oncologic resection for colorectal cancer. World Journal of Surgical Oncology, 17:20-25.

20. Rollins KE, Javanmard-Emamghissi $H$ and Lobo DN. (2018): Impact of mechanicalbowel preparation in elective colorectal surgery: a meta-analysis. World J Gastroenterol., 24:519536.

21. Rollins KE, Javanmard-Emamghissi H, Acheson AG and Lobo DN. (2019): The Role of Oral Antibiotic Preparation in Elective Colorectal Surgery. Annals of Surgery, 270: 43-58.

22. Scarborough JE, Mantyh CR, Sun $Z$ and Migaly J. (2015): Combined mechanical and oral antibiotic bowel preparation reduces incisional surgical site infection and anastomotic leak rates after elective colorectal resection: an analysis of colectomy-targeted ACS NSQIP. Ann Surg., 262:331-337.

23. Slim K, Vicaut E and Launay-Savary MV. (2010): Updated systematic review andmetaanalysis of randomized clinical trials on the role of mechanical bowelpreparation before colorectal surgery. Ann Surg., 249:203-209.

24. Suleyman O, Gulpinara K, Ozisa E, Sahlia Z, Kesiklia A, Korkmaza A and Gecim E. (2016): Original Research the effects of preoperative oral antibiotic use on the development of surgical site infection after elective colorectal resections: Aretrospective cohort analysis in consecutively operated 90 patients. International Journal of Surgery, 33: 102-108.

25. Sun WC, Hsu HH, Liu HC and Liu CK. (2018): Can mechanical bowel preparation with oral antibiotics reduce surgical site infection and anastomotic leakage rates following elective colorectal resections?. Formos J Surg., 51:21-5.

26. Uchino M, Ikeuchi $H$ and Bando $T$ (2019): Efficacy of preoperative oral antibiotic prophylaxis for the prevention of surgical site infections in patients with Crohn's disease a randomized controlled trial. Ann Surg., 269:420-426. 


\section{مقارنة فعالية تحضير الأمعاء الميكانيكية مع أو بلدوز المضادات الحيوية

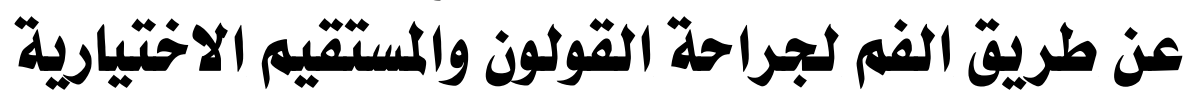

عبد الله بركات عبد الله بسيونى, محمد محسن سالم, أيمن حلمى ابراهيم قسم الجراحة العامة, كلية الطب، جامعة الأزهر

E-mail: abdallah_bassuny9090@gmail.com

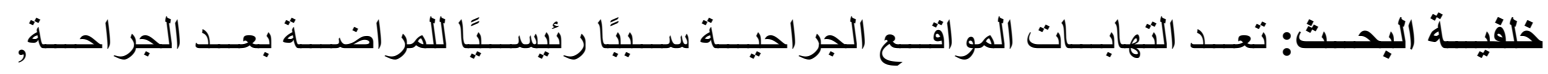

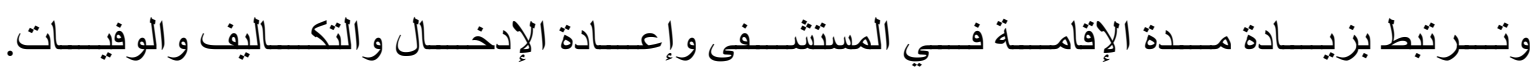

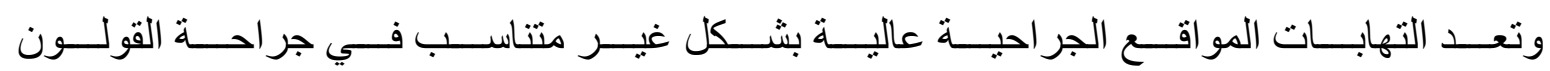

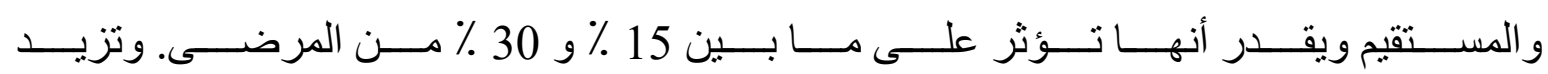

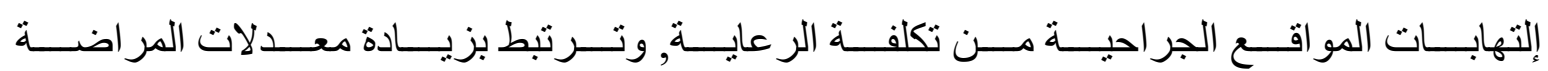
و الوفيات, وهي ثالث أكثر أنواع عدوى المستشفيات شيو عًا.

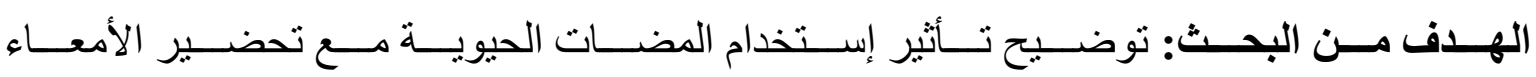
الميكانيكى علي نتائج المريض بعد جر احة القولون و المستقيم الاختيارية.

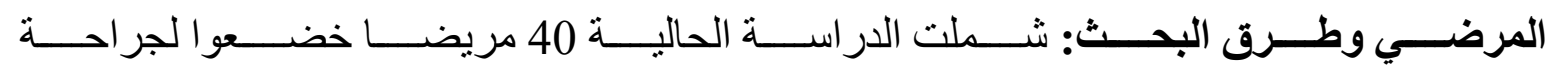

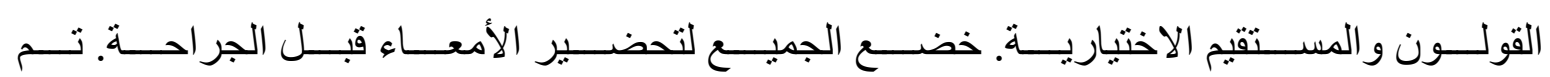

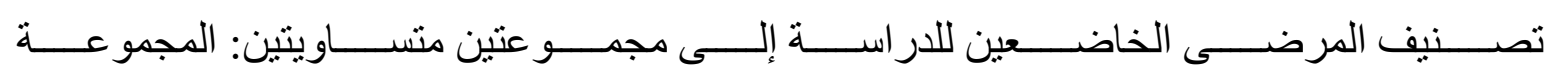

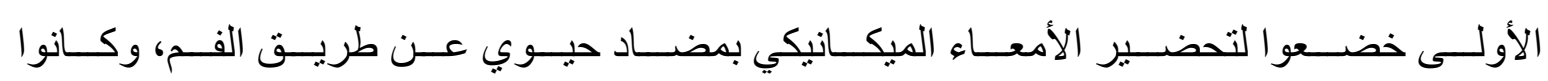

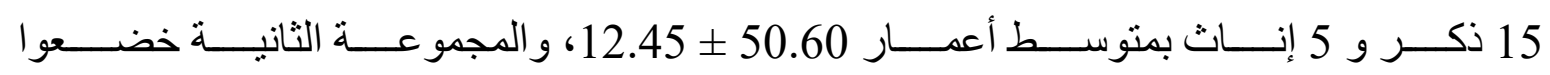

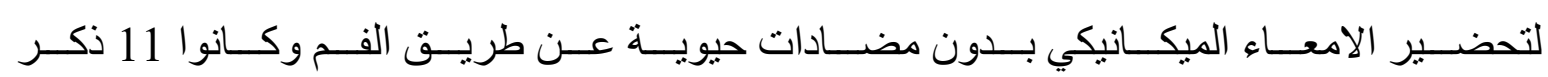
و 9 اناث بمتوسط اعمار 8.94 ـ 48.50.

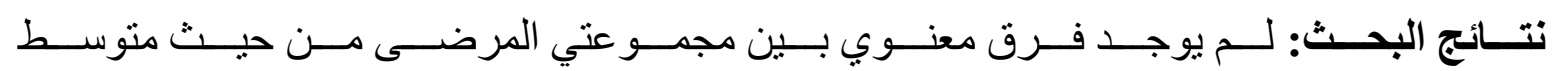

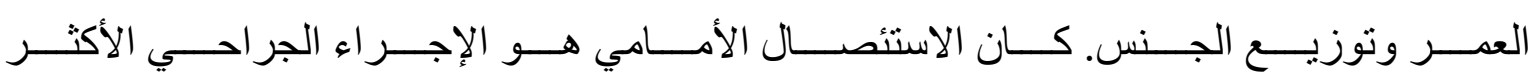

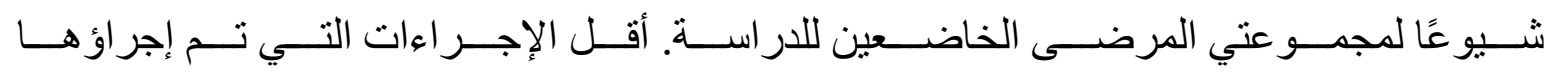

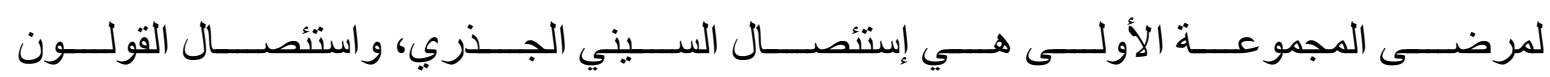

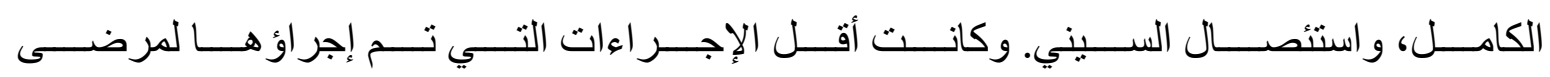

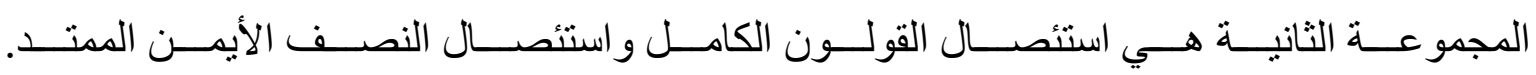




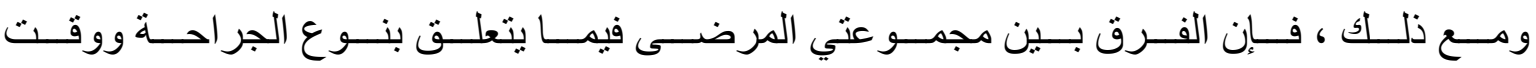

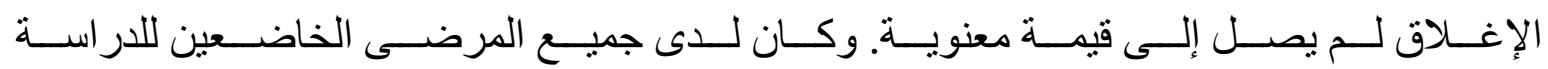

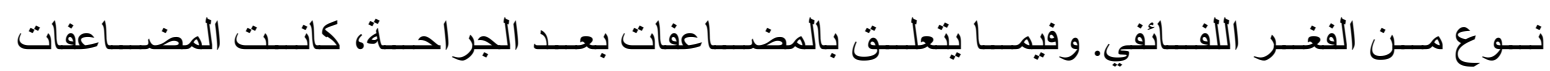

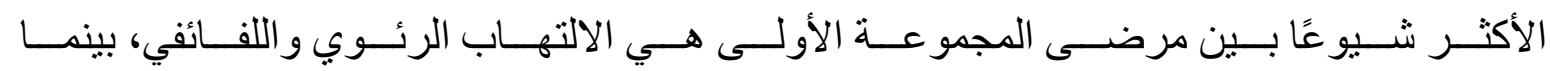

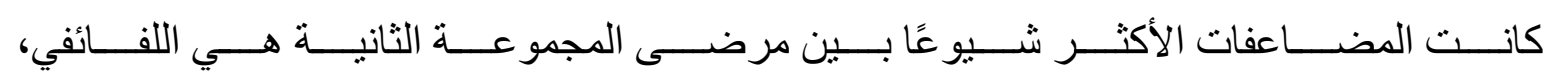

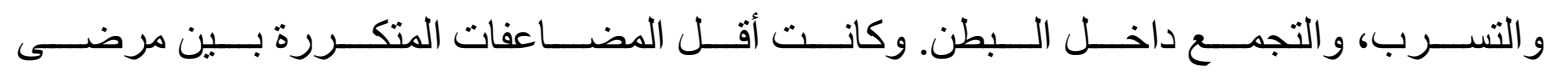

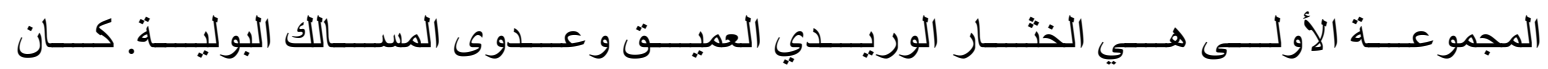

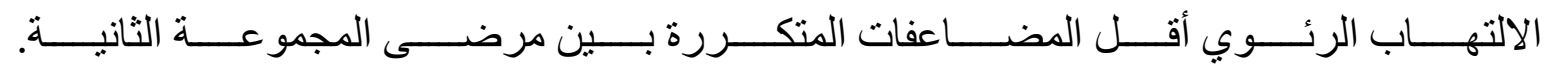

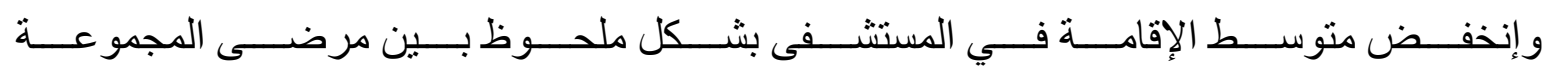
الإولي.

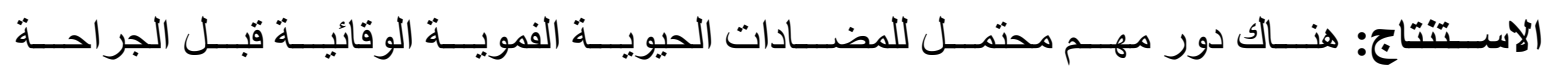

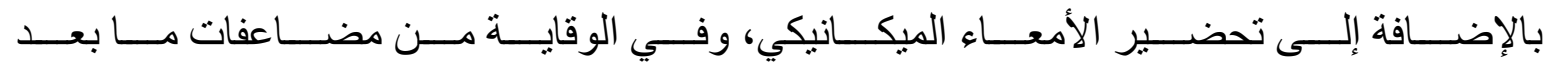
الجر احة في جر احة القولون و المستقيم الاختيارية.

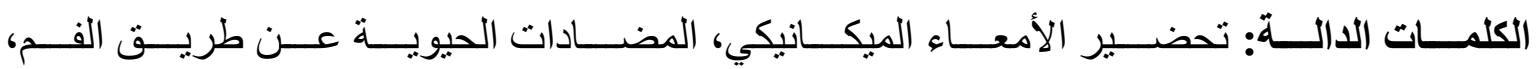
جر احة القولون و المستقيم الاختبارية. 